U.S. DEPARTMENT OF COMMERCE

Technology Administration

National Institute of Standards and Technology

FIPS PUB 180

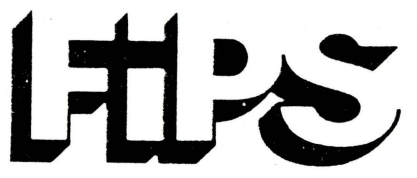

FEDERAL INFORMATION PROCESSING STANDARDS PUBLICATION

\title{
SECURE HASH STANDARD
}

Category: Computer Security

1993 MAY 11

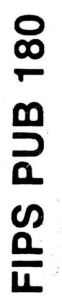




\section{FIPS PUB 180}

\section{FEDERAL INFORMATION PROCESSING STANDARDS PUBLICATION}

\section{SECURE HASH STANDARD}

\section{Category: Computer Security}

Computer Systems Laboratory

National Institute of Standards and Technology

Gaithersburg, MD 20899

Issued May 11, 1993

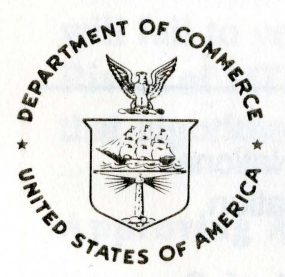

U.S. Department of Commerce

Ronald H. Brown, Secretary

National Institute of Standards and Technology

Raymond G. Kammer, Acting Director 

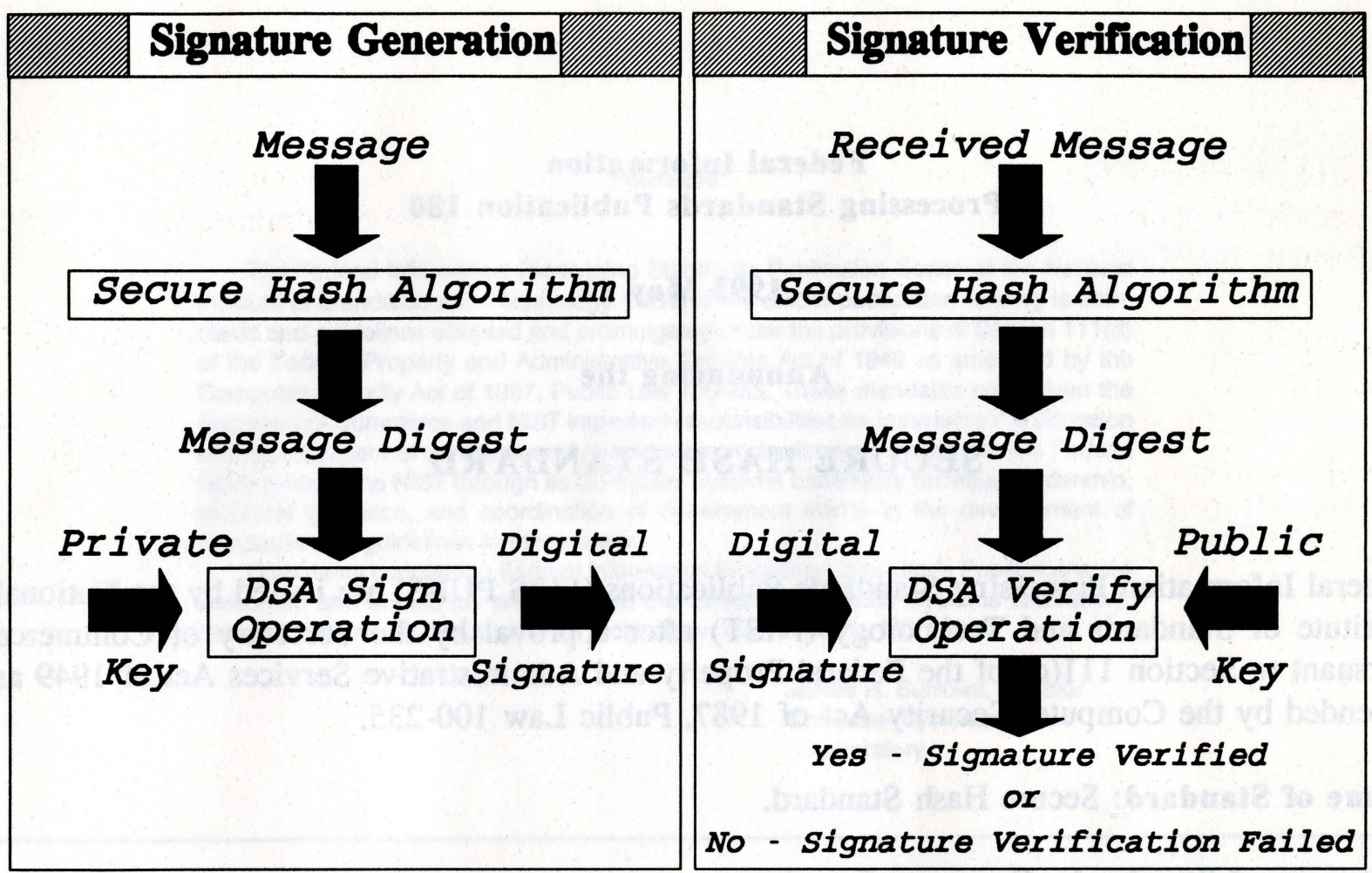

Figure 1: Using the SHA with the DSA

Maintenance Agency: U.S. Department of Commerce, National Institute of Standards and Technology, Computer Systems Laboratory.

Applicability: This standard is applicable to all Federal departments and agencies for the protection of unclassified information that is not subject to section 2315 of Title 10, United States Code, or section 3502(2) of Title 44, United States Code. This standard is required for use with the Digital Signature Algorithm (DSA) as specified in the Digital Signature Standard (DSS) and whenever a secure hash algorithm is required for federal applications. Private and commercial organizations are encouraged to adopt and use this standard.

Applications: The SHA may be used with the DSA in electronic mail, electronic funds transfer, software distribution, data storage, and other applications which require data integrity assurance and data origin authentication. The SHA may also be used whenever it is necessary to generate a condensed version of a message.

Implementations: The SHA may be implemented in software, firmware, hardware, or any combination thereof. Only implementations of the SHA that are validated by NIST will be 
considered as complying with this standard. Information about the requirements for validating implementations of this standard can be obtained from the National Institute of Standards and Technology, Computer Systems Laboratory, Attn: SHS Validation, Gaithersburg, MD 20899.

Export Control: Implementations of this standard are subject to Federal Government export controls as specified in Title 15, Code of Federal Regulations, Parts 768 through 799. Exporters are advised to contact the Department of Commerce, Bureau of Export Administration for more information.

Patents: Implementations of the SHA in this standard may be covered by U.S. and foreign patents.

Implementation Schedule: This standard becomes effective October 15, 1993.

Specifications: Federal Information Processing Standard (FIPS 180) Secure Hash Standard (affixed).

Cross Index:

a. FIPS PUB 46-1, Data Encryption Standard.

b. FIPS PUB 73, Guidelines for Security of Computer Applications.

c. Draft FIPS PUB 140-1, Security Requirements for Cryptographic Modules.

d. FIPS PUB XX, Digital Signature Standard.

Qualifications: While it is the intent of this standard to specify a secure hash algorithm, conformance to this standard does not assure that a particular implementation is secure. The responsible authority in each agency or department shall assure that an overall implementation provides an acceptable level of security. This standard will be reviewed every five years in order to assess its adequacy.

Waiver Procedure: Under certain exceptional circumstances, the heads of Federal departments and agencies may approve waivers to Federal Information Processing Standards (FIPS). The head of such agency may redelegate such authority only to a senior official designated pursuant to section 3506(b) of Title 44, United States Code. Waiver shall be granted only when:

a. Compliance with a standard would adversely affect the accomplishment of the mission of an operator of a Federal computer system; or

b. Compliance with a standard would cause a major adverse financial impact on the operator which is not offset by Government-wide savings. 
Agency heads may act upon a written waiver request containing the information detailed above. Agency heads may also act without a written waiver request when they determine that conditions for meeting the standard cannot be met. Agency heads may approve waivers only by a written decision which explains the basis on which the agency head made the required finding(s). A copy of each decision, with procurement sensitive or classified portions clearly identified, shall be sent to: National Institute of Standards and Technology; ATTN: FIPS Waiver Decisions, Technology Building, Room B-154, Gaithersburg, MD 20899.

In addition, notice of each waiver granted and each delegation of authority to approve waivers shall be sent promptly to the Committee on Government Operations of the House of Representatives and the Committee on Government Affairs of the Senate and shall be published promptly in the Federal Register.

When the determination on a waiver applies to the procurement of equipment and/or services, a notice of the waiver determination must be published in the Commerce Business Daily as a part of the notice of solicitation for offers of an acquisition or, if the waiver determination is made after that notice is published, by amendment to such notice.

A copy of the waiver, any supporting documents, the document approving the waiver and any accompanying documents, with such deletions as the agency is authorized and decides to make under 5 United States Code Section 552(b), shall be part of the procurement documentation and retained by the agency.

Where to Obtain Copies of the Standard: Copies of this publication are for sale by the National Technical Information Service, U.S. Department of Commerce, Springfield, VA 22161. When ordering, refer to Federal Information Processing Standards Publication 180 (FIPSPUB180), and identify the title. When microfiche is desired, this should be specified. Prices are published by NTIS in current catalogs and other issuances. Payment may be made by check, money order, deposit account or charged to a credit card accepted by NTIS. 


\title{
Federal Information \\ Processing Standards Publication 180
}

1993 May 11

\author{
Specifications for the
}

\section{SECURE HASH STANDARD}

\section{INTRODUCTION}

The Secure Hash Algorithm (SHA) is required for use with the Digital Signature Algorithm (DSA) as specified in the Digital Signature Standard (DSS) and whenever a secure hash algorithm is required for federal applications. For a message of length $<2^{64}$ bits, the SHA produces a 160 bit condensed representation of the message called a message digest. The message digest is used during generation of a signature for the message. The SHA is also used to compute a message digest for the received version of the message during the process of verifying the signature. Any change to the message in transit will, with very high probability, result in a different message digest, and the signature will fail to verify.

The SHA is designed to have the following properties: it is computationally infeasible to find a message which corresponds to a given message digest, or to find two different messages which produce the same message digest.

\section{BIT STRINGS AND INTEGERS}

The following terminology related to bit strings and integers will be used:

a. A hex digit is an element of the set $\{0,1, \ldots, 9, \mathrm{~A}, \ldots, \mathrm{F}\}$. A hex digit is the representation of a 4-bit string. Examples: $7=0111, A=1010$.

b. A word equals a 32-bit string which may be represented as a sequence of 8 hex digits. To convert a word to 8 hex digits each 4-bit string is converted to its hex equivalent as described in (a) above. Example:

$$
10100001000000111111111000100011 .=\mathrm{A} 103 \mathrm{FE} 23
$$

c. An integer between 0 and $2^{32}-1$ inclusive may be represented as a word. The least significant four bits of the integer are represented by the right-most hex digit of the word representation. Example: the integer $291=2^{8}+2^{5}+2^{1}+2^{0}=256+32+2+1$ is represented by the hex word, 00000123 . 
If $z$ is an integer, $0 \leq z<2^{64}$, then $z=2^{32} x+y$ where $0 \leq x<2^{32}$ and $0 \leq y<2^{32}$. Since $\mathrm{X}$ and $\mathrm{y}$ can be represented as words $\mathrm{X}$ and $\mathrm{Y}$, respectively, $\mathrm{z}$ can be represented as the pair of words $(\mathrm{X}, \mathrm{Y})$.

d. $\quad$ block $=512$-bit string. A block (e.g., B) may be represented as a sequence of 16 words.

\section{OPERATIONS ON WORDS}

The following logical operators will be applied to words:

a. Bitwise logical word operations

$$
\begin{array}{ll}
X \wedge \mathrm{Y} & =\text { bitwise logical "and" of } \mathrm{X} \text { and } \mathrm{Y} . \\
\mathrm{X} \vee \mathrm{Y} & =\text { bitwise logical "inclusive-or" of } \mathrm{X} \text { and } \mathrm{Y} . \\
\mathrm{X} X \mathrm{XOR} \mathrm{Y} & =\text { bitwise logical "exclusive-or" of } \mathrm{X} \text { and } \mathrm{Y} . \\
\sim \mathrm{X} & =\text { bitwise logical "complement" of } \mathrm{X} .
\end{array}
$$

\section{Exam ple:}

$$
\begin{array}{ll}
\text { XOR } & 01101100101110011101001001111011 \\
= & 00001001011110001011101111001100
\end{array}
$$

b. The operation $X+Y$ is defined as follows: words $\mathrm{X}$ and $\mathrm{Y}$ represent integers $\mathrm{x}$ and $\mathrm{y}$, where $0 \leq x<2^{32}$ and $0 \leq y<2^{32}$. For positive integers $n$ and $m$, let $n \bmod m$ be the remainder upon dividing $\mathrm{n}$ by $\mathrm{m}$. Compute

$$
z=(x+y) \bmod 2^{32} \text {. }
$$

Then $0 \leq \mathrm{z}<2^{32}$. Convert $\mathrm{z}$ to a word, $\mathrm{Z}$, and define $\mathrm{Z}=\mathrm{X}+\mathrm{Y}$.

c. The circular left shift operation $S^{n}(X)$, where $X$ is a word and $n$ is an integer with $0 \leq$ $\mathrm{n}<32$, is defined by

$$
S^{n}(X)=(X<<n) \vee(X>32-n)
$$

In the above, $\mathrm{X} \ll \mathrm{n}$ is obtained as follows: discard the left-most $\mathrm{n}$ bits of $\mathrm{X}$ and then pad the result with $n$ zeroes on the right (the result will still be 32 bits). $X \gg n$ is obtained by discarding the right-most $n$ bits of $X$ and then padding the result with $n$ 
zeroes on the left. Thus $S^{n}(X)$ is equivalent to a circular shift of $\mathrm{X}$ by $\mathrm{n}$ positions to the left.

\section{MESSAGE PADDING}

The SHA is used to compute a message digest for a message or data file that is provided as input. The message or data file should be considered to be a bit string. The length of the message is the number of bits in the message (the empty message has length 0 ). If the number of bits in a message is a multiple of 8 , for compactness we can represent the message in hex. The purpose of message padding is to make the total length of a padded message a multiple of 512. The SHA sequentially processes blocks of 512 bits when computing the message digest. The following specifies how this padding shall be performed. As a summary, a "1" followed by $\mathrm{m}$ "0"s followed by a 64-bit integer are appended to the end of the message to produce a padded message of length $512 \times \mathrm{n}$. The 64-bit integer is $l$, the length of the original message. The padded message is then processed by the SHA as $\mathrm{n}$ 512-bit blocks.

Suppose a message has length $l<2^{64}$. Before it is input to the SHA, the message is padded on the right as follows:

a. "1" is appended. Example: if the original message is "01010000", this is padded to "010100001".

b. "0"s are appended. The number of " 0 "s will depend on the original length of the message. The last 64 bits of the last 512-bit block are reserved for the length $l$ of the original message.

Example: Suppose the original message is the bit string

$$
0110000101100010011000110110010001100101 .
$$

After step (a) this gives

$$
01100001011000100110001101100100011001011 .
$$

Since $l=40$, the number of bits in the above is 41 and 407 "0"s are appended, making

\begin{tabular}{|c|c|c|c|}
\hline 61626364 & 65800000 & 00000000 & 0000 \\
\hline 00000000 & 00000000 & 00000000 & 00000000 \\
\hline 00000000 & 00000000 & 00000000 & 00000000 \\
\hline 00000000 & 00000000. & & \\
\hline
\end{tabular}
the total now 448. This gives (in hex)

c. Obtain the 2-word representation of $l$, the number of bits in the original message. If $l<2^{32}$ then the first word is all zeroes. Append these two words to the padded message. 
Exam ple: Suppose the original message is as in (b). Then $l=\mathbf{4 0}$ (note that $l$ is computed before any padding). The two-word representation of 40 is hex 0000000000000028 . Hence the final padded message is hex

$\begin{array}{llll}61626364 & 65800000 & 00000000 & 00000000 \\ 00000000 & 00000000 & 00000000 & 00000000 \\ 00000000 & 00000000 & 00000000 & 00000000 \\ 00000000 & 00000000 & 00000000 & 00000028 .\end{array}$

The padded message will contain $16 n$ words for some $n>0$. The padded message is regarded as a sequence of $n$ blocks $M_{1}, M_{2}, \ldots, M_{n}$, where each $M_{i}$ contains 16 words and $M_{1}$ contains the first characters (or bits) of the message.

\section{FUNCTIONS USED}

A sequence of logical functions $f_{0}, f_{1}, \ldots, f_{79}$ is used in the SHA. Each $f_{t}, 0 \leq t \leq 79$, operates on three 32-bit words and produces a 32-bit word as output. $f_{t}$ is defined as follows: for words, $\mathrm{B}, \mathrm{C}, \mathrm{D}$,

$$
\begin{array}{ll}
\mathrm{f}_{\mathrm{t}}(\mathrm{B}, \mathrm{C}, \mathrm{D})=(\mathrm{B} \wedge \mathrm{C}) \vee(\sim \mathrm{B} \wedge \mathrm{D}) & (0 \leq \mathrm{t} \leq 19) \\
\mathrm{f}_{\mathrm{t}}(\mathrm{B}, \mathrm{C}, \mathrm{D})=\mathrm{B} \text { XOR } \quad \mathrm{C} \quad \mathrm{XOR} \quad \mathrm{D} & (20 \leq \mathrm{t} \leq 39) \\
\mathrm{f}_{\mathrm{t}}(\mathrm{B}, \mathrm{C}, \mathrm{D})=(\mathrm{B} \wedge \mathrm{C}) \vee(\mathrm{B} \wedge \mathrm{D}) \vee(\mathrm{C} \wedge \mathrm{D}) & (40 \leq \mathrm{t} \leq 59) \\
\mathrm{f}_{\mathrm{t}}(\mathrm{B}, \mathrm{C}, \mathrm{D})=\mathrm{B} \quad \mathrm{XOR} \text { C XOR } \mathrm{X} & (60 \leq \mathrm{t} \leq 79)
\end{array}
$$

\section{CONSTANTS USED}

A sequence of constant words $K_{0}, K_{1}, \ldots, K_{79}$ is used in the SHA. In hex these are given by

$$
\begin{array}{ll}
\mathbf{K}_{\mathbf{t}}=5 \text { A827999 } & (0 \leq \mathrm{t} \leq 19) \\
\mathbf{K}_{\mathbf{t}}=6 \text { ED } & (20 \leq \mathrm{t} \leq 39) \\
\mathrm{K}_{\mathbf{t}}=8 \text { F1BBC } & (40 \leq \mathrm{t} \leq 59) \\
\mathrm{K}_{\mathbf{t}}=\text { CA62C1D } & (60 \leq \mathrm{t} \leq 79) .
\end{array}
$$




\section{COMPUTING THE MESSAGE DIGEST}

The message digest is computed using the final padded message. The computation uses two buffers, each consisting of five 32-bit words, and a sequence of eighty 32-bit words. The words of the first 5-word buffer are labeled A,B,C,D,E. The words of the second 5-word buffer are labeled $\mathrm{H}_{0}, \mathrm{H}_{1}, \mathrm{H}_{2}, \mathrm{H}_{3}, \mathrm{H}_{4}$. The words of the 80 -word sequence are labeled $\mathrm{W}_{0}, \mathrm{~W}_{1}, \ldots, \mathrm{W}_{79}$. A single word buffer TEMP is also employed.

To generate the message digest, the 16-word blocks $M_{1}, M_{2}, \ldots, M_{n}$ defined in Section 4 are processed in order. The processing of each $\mathrm{M}_{\mathrm{i}}$ involves 80 steps.

Before processing any blocks, the $\left\{\mathrm{H}_{\mathrm{j}}\right\}$ are initialized as follows: in hex,

$$
\begin{aligned}
& \mathbf{H}_{0}=67452301 \\
& \mathbf{H}_{1}=\text { EFCDAB89 } \\
& \mathbf{H}_{2}=98 \mathrm{BADCFE} \\
& \mathbf{H}_{3}=10325476 \\
& \mathbf{H}_{4}=\text { C3D } 2 \mathrm{E} 1 \mathrm{~F} 0 .
\end{aligned}
$$

Now $\mathbf{M}_{1}, \mathbf{M}_{2}, \ldots, \mathbf{M}_{\mathrm{n}}$ are processed. To process $\mathbf{M}_{\mathrm{i}}$, we proceed as follows:

a. Divide $\mathrm{M}_{\mathrm{i}}$ into 16 words $\mathrm{W}_{0}, \mathrm{~W}_{1}, \ldots, \mathrm{W}_{15}$, where $\mathrm{W}_{0}$ is the left-most word.

b. For $\mathrm{t}=16$ to 79 let $\mathrm{W}_{\mathrm{t}}=\mathrm{W}_{\mathrm{t}-3}$ XOR $\mathrm{W}_{\mathrm{t}-8}$ XOR $\mathrm{W}_{\mathrm{t}-14} \mathrm{XOR}_{\mathrm{t}-16}$.

c. Let $\mathrm{A}=\mathrm{H}_{0}, \quad B=\mathrm{H}_{1}, \quad \mathrm{C}=\mathrm{H}_{2}, \quad \mathrm{D}=\mathrm{H}_{3}, \quad \mathrm{E}=\mathrm{H}_{4}$.

d. For $\mathrm{t}=0$ to 79 do

$$
\begin{aligned}
& \text { TEMP }=S^{5}(A)+f_{t}(B, C, D)+E+W_{t}+K_{t} \\
& E=D ; \quad D=C ; C=S^{30}(B) ; \quad B=A ; A=T E M P
\end{aligned}
$$

e. Let $\mathrm{H}_{0}=\mathrm{H}_{0}+\mathrm{A}, \mathrm{H}_{1}=\mathrm{H}_{1}+\mathrm{B}, \mathrm{H}_{2}=\mathrm{H}_{2}+\mathrm{C}, \mathrm{H}_{3}=\mathrm{H}_{3}+\mathrm{D}, \mathrm{H}_{4}=\mathrm{H}_{4}+\mathrm{E}$.

After processing $M_{n}$, the message digest is the 160-bit string represented by the 5 words $\begin{array}{lllll}\mathrm{H}_{0} & \mathrm{H}_{1} & \mathrm{H}_{2} & \mathrm{H}_{3} & \mathrm{H}_{4}\end{array}$ 


\section{ALTERNATE METHOD OF COMPUTATION}

The above assumes that the sequence $\mathrm{W}_{0}, \ldots, \mathrm{W}_{79}$ is implemented as an array of eighty 32-bit words. This is efficient from the standpoint of minimization of execution time, since the addresses of $\mathrm{W}_{\mathrm{t}-3}, \ldots, \mathrm{W}_{\mathrm{t}-16}$ in step (b) are easily computed. If space is at a premium, an alternative is to regard $\left\{\mathrm{W}_{\mathrm{t}}\right\}$ as a circular queue, which may be implemented using an array of sixteen 32-bit words $\mathrm{W}[0], \ldots \mathrm{W}[15]$. In this case, in hex let MASK $=0000000 \mathrm{~F}$. Then processing of $\mathrm{M}_{\mathrm{i}}$ is as follows:

a. Divide $\mathrm{M}_{\mathrm{i}}$ into 16 words $\mathrm{W}[0], \ldots, \mathrm{W}[15]$, where $\mathrm{W}[0]$ is the left-most word.

b. Let $\mathrm{A}=\mathrm{H}_{0}, \mathrm{~B}=\mathrm{H}_{1}, \mathrm{C}=\mathrm{H}_{2}, \mathrm{D}=\mathrm{H}_{3}, \mathrm{E}=\mathrm{H}_{4}$.

c. For $\mathrm{t}=0$ to 79 do

$$
\begin{aligned}
& \begin{array}{r}
\mathrm{s}=\mathrm{t} \wedge \mathrm{MASK} ; \\
\text { if }(\mathrm{t} \geq 16) \mathrm{W}[\mathrm{s}]=\mathrm{W}[(\mathrm{s}+13) \wedge \text { MASK }] \text { XOR W }[(\mathrm{s}+8) \wedge \mathrm{MASK}] \text { XOR } \\
\mathrm{W}[(\mathrm{s}+2) \wedge \mathrm{MASK}] \text { XOR W[s]; }
\end{array} \\
& \begin{aligned}
\text { TEMP }=\mathrm{S}^{5}(\mathrm{~A})+\mathrm{f}_{\mathrm{t}}(\mathrm{B}, \mathrm{C}, \mathrm{D})+\mathrm{E}+\mathrm{W}[\mathrm{s}]+\mathrm{K}_{\mathrm{t}} \\
\mathrm{E}=\mathrm{D} ; \mathrm{D}=\mathrm{C} ; \mathrm{C}=\mathrm{S}^{30}(\mathrm{~B}) ; \mathrm{B}=\mathrm{A} ; \mathrm{A}=\mathrm{TEMP} ;
\end{aligned}
\end{aligned}
$$

d. Let $\mathrm{H}_{0}=\mathrm{H}_{0}+\mathrm{A}, \mathrm{H}_{1}=\mathrm{H}_{1}+\mathrm{B}, \mathrm{H}_{2}=\mathrm{H}_{2}+\mathrm{C}, \mathrm{H}_{3}=\mathrm{H}_{3}+\mathrm{D}, \mathrm{H}_{4}=\mathrm{H}_{4}+\mathrm{E}$.

\section{COMPARISON OF METHODS}

The methods of Sections 7 and 8 yield the same message digest. Although using the method of Section 8 saves sixty-four 32-bit words of storage, it is likely to lengthen execution time due to the increased complexity of the address computations for the $\{\mathrm{W}[\mathrm{t}]\}$ in step (c). Other computation methods which give identical results may be implemented in conformance with the standard. 


\section{APPENDIX A. A SAMPLE MESSAGE AND ITS MESSAGE DIGEST}

This appendix is for informational purposes only and is not required to meet the standard.

Let the message be the ASCII binary-coded form of "abc", i.e.,

$$
011000010110001001100011 .
$$

This message has length $l=24$. In step (a) of Section 4, we append "1". In step (b) we append 423 "0"s. In step (c) we append hex 0000000000000018 , the 2-word representation of 24. Thus the final padded message consists of one block, so that $n=1$ in the notation of Section 4 . The single block has hex words

$$
\begin{array}{ll}
\mathrm{W}[0] & =61626380 \\
\mathrm{~W}[1] & =00000000 \\
\mathrm{~W}[2] & =00000000 \\
\mathrm{~W}[3] & =00000000 \\
\mathrm{~W}[4] & =00000000 \\
\mathrm{~W}[5] & =00000000 \\
\mathrm{~W}[6] & =00000000 \\
\mathrm{~W}[7] & =00000000 \\
\mathrm{~W}[8] & =00000000 \\
\mathrm{~W}[9] & =00000000 \\
\mathrm{~W}[10] & =00000000 \\
\mathrm{~W}[11] & =00000000 \\
\mathrm{~W}[12] & =00000000 \\
\mathrm{~W}[13] & =00000000 \\
\mathrm{~W}[14] & =00000000 \\
\mathrm{~W}[15] & =00000018 .
\end{array}
$$

The initial hex values of $\left\{\mathrm{H}_{\mathrm{i}}\right\}$ are

$$
\begin{aligned}
& \mathrm{H}_{0}=67452301 \\
& \mathrm{H}_{1}=\text { EFCDAB } 89 \\
& \mathrm{H}_{2}=98 \mathrm{BADCFE} \\
& \mathrm{H}_{3}=10325476 \\
& \mathrm{H}_{4}=\text { C3D } 2 \mathrm{E} 1 \mathrm{~F} 0 .
\end{aligned}
$$

The hex values of A,B,C,D,E after pass $t$ of the "for $t=0$ to 79" loop (step (d) of Section 7 or (c) of Section 8) are 
A

\begin{tabular}{|c|c|c|}
\hline & $\bullet^{\circ}$ & \\
\hline & $=$ & \\
\hline & $=$ & \\
\hline & $=$ & CDI \\
\hline & $=$ & CFD499I \\
\hline & $=$ & $3 F C 7 C A$ \\
\hline & $=$ & $993 \mathrm{E} 30 \mathrm{CJ}$ \\
\hline & $=$ & $9 \mathrm{E} 8 \mathrm{C} 07$ \\
\hline & $=$ & $\mathrm{B} 6 \mathrm{AE}$ \\
\hline & $=$ & 835 \\
\hline & $=10:$ & FBD \\
\hline & $=1$ & 631 \\
\hline & $=1$ & 46 \\
\hline & $=1$ & 91 \\
\hline & $=14:$ & 196 \\
\hline & $=1$ & $20 B$ \\
\hline & $=$ & ED2F \\
\hline & $=$ & $565 \mathrm{I}$ \\
\hline & $=$ & 550 \\
\hline & $=$ & FE0 \\
\hline & $=$ & B4D \\
\hline & $=$ & 43 \\
\hline & $=$ & F71 \\
\hline & $=$ & 7759 \\
\hline & $=$ & $45 \mathrm{~A} 7$ \\
\hline & $=$ & CCEA \\
\hline & $=$ & $02 \mathrm{D}$ \\
\hline & $=$ & 0700 \\
\hline & $=2$ & 301 \\
\hline & $=$ & B89 \\
\hline & $=$ & 669 \\
\hline & $=3$ & D93. \\
\hline & $=3$ & DB81 \\
\hline & $=3$ & $99 C 8$ \\
\hline & $=3$ & 6BE6A \\
\hline & $=$ & $\mathrm{C} 01 \mathrm{CC}$ \\
\hline & $=3$ & $6433 \mathrm{FD}$ \\
\hline & $=3$ & $0 A 33 \mathrm{CCF}$ \\
\hline & $=3$ & $4 \mathrm{BF} 58 \mathrm{D}$ \\
\hline & $=3$. & EBBD 52 \\
\hline & 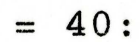 & $825 \mathrm{~A} 34$ \\
\hline & & $\mathrm{B} 62 \mathrm{CBE}$ \\
\hline & 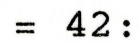 & AA 3 F97 \\
\hline & 4 & FE1D02 \\
\hline & $=$ & $57 A D 5$ \\
\hline & & $93 \mathrm{EBB}$ \\
\hline & & \\
\hline
\end{tabular}

B

C

67452301

0116 FC33

8990536D

A1390F08

CDD8E11B

CFD499DE

3FC7CA 40

993E30C1

9E8C07D4

4B6AE328

8351 F929

FBDA9E89

63188FE4

4607B664

$9128 \mathrm{~F} 695$

$196 \mathrm{BEE} 77$

20 BDD $62 \mathrm{~F}$

ED2FF4A3

565DF73C

550B1E7F

FE0F9E4B

B4D4C943

43993572

F7106486

$775924 \mathrm{E} 6$

45A7EF 23

CCEAD 674

02D0C6D1

$070 \mathrm{C} 437 \mathrm{~F}$

$301 \mathrm{E} 90 \mathrm{BE}$

B898C685

669723E2

D9316F96

DB81A5C7

99C8DFB2

6BE6AE0 7

C01CC62C

6433FDD0

OA 33 CCF 7

4BF58DC8

EBBD 5233

825A3460

B62 CBB9 3

AA3F9707

FE1D0273

57AD526B

93EBBE3F
7BF36AE2

59D148C 0

C $045 B F 0 C$

$626414 \mathrm{DB}$

$284 \mathrm{E} 43 \mathrm{C} 2$

F3763846

B3F 52677

OFF1F290

$664 \mathrm{~F} 8 \mathrm{C} 30$

27A301F5

12DAB8CA

60D47E4A

7EF6A7A2

$18 \mathrm{C} 623 \mathrm{~F} 9$

1181ED99

644A3DA5

C65AFB9D

C82F758B

FB4BFD2 8

15977DCF

D542C79F

FF83E792

ED353250

90E64D5C

BDC41921

9DD64939

D169FBC 8

333AB59D

4 0B431B4

C1C310DF

8C07A42F

6E2 631A1

99A5C8F8

B64C5BE5

F6E06971

A $67237 \mathrm{EC}$

DAF9AB81

3007318B

190 CFF7 4

C28CF33D

12FD 6372

FAEF548C

20968D18

ED8B2EE4

EA 8FE5C1

FF87409C

D5EB549A
E

10325476

98BADCFE

7BF36AE2

59D148C 0

C $045 \mathrm{BF} 0 \mathrm{C}$

$626414 \mathrm{DB}$

$284 \mathrm{E} 43 \mathrm{C} 2$

F3763846

B3F52 677

OFF $1 F 290$

$664 \mathrm{~F} 8 \mathrm{C} 30$

27A301F5

12DAB8CA

60D47E4A

7EF6A7A2

$18 \mathrm{C} 623 \mathrm{~F} 9$

1181ED99

644A3DA5

C65AFB9D

C82F758B

FB4BFD2 8

15977DCF

D542C79F

FF83E792

ED353250

90E64D5C

BDC 41921

9DD64939

D169FBC8

333AB59D

40B431B4

C1C310DF

8C07A42F

6E2 631A1

99A5C8F8

B64C5BE5

F6E06971

A67237EC

DAF9AB81

$3007318 \mathrm{~B}$

190 CFF7 4

C28CF33D

12 FD 6372

FAEF $548 \mathrm{C}$

20968D18

ED8B2EE4

EA8FE5C1 


\begin{tabular}{|c|c|c|c|c|c|c|}
\hline$t$ & $=47:$ & $875586 \mathrm{D} 2$ & F9ADF47B & E4FAEF 8F & D5EB549A & FF87409C \\
\hline$t$ & $=48:$ & $\mathrm{D} 0 \mathrm{~A} 22 \mathrm{FFB}$ & $875586 \mathrm{D} 2$ & FE6B7D1E & E4FAEF 8F & D5EB549A \\
\hline$t$ & $=49:$ & C12B 6426 & $\mathrm{D} 0 \mathrm{~A} 22 \mathrm{FFB}$ & A1D561B4 & FE6B7D1E & E4FAEF 8F \\
\hline$t$ & $=50:$ & EBC 90281 & C12B 6426 & F4288BFE & A1D561B4 & FE6B7D1E \\
\hline t & $=51:$ & E7D0EC05 & EBC9 0281 & B04AD 909 & F4288BFE & $\mathrm{A} 1 \mathrm{D} 561 \mathrm{~B} 4$ \\
\hline$t$ & $=52:$ & 7СВ98E55 & E7D0EC05 & 7AF2 40A0 & B0 4AD909 & F4288BFE \\
\hline$t$ & $=53:$ & OD48DBA2 & 7 СВ98E55 & $79 F 43 \mathrm{~B} 01$ & $7 \mathrm{AF} 240 \mathrm{AO}$ & B04AD 909 \\
\hline$t$ & $=54:$ & $\mathrm{C} 2 \mathrm{D} 477 \mathrm{BF}$ & OD4 8DBA2 & $5 F 2 E 6395$ & $79 \mathrm{~F} 43 \mathrm{~B} 01$ & $7 \mathrm{AF} 240 \mathrm{AO}$ \\
\hline$t$ & $=55:$ & $236 \mathrm{BD} 48 \mathrm{D}$ & $\mathrm{C} 2 \mathrm{D} 477 \mathrm{BF}$ & $835236 \mathrm{E} 8$ & $5 F 2$ E6395 & $79 \mathrm{~F} 43 \mathrm{~B} 01$ \\
\hline$t$ & $=56:$ & $9 \mathrm{~B} 4364 \mathrm{D} 6$ & $236 \mathrm{BD} 48 \mathrm{D}$ & F0B51DEF & $835236 \mathrm{E} 8$ & $5 F 2$ E6395 \\
\hline t & $=57:$ & $5 B 8 C 33 C 9$ & $9 B 4364 \mathrm{D} 6$ & 48DAF 523 & F0B51DEF & $835236 \mathrm{E} 8$ \\
\hline$t$ & $=58:$ & BE2A4 656 & $5 B 8 C 33 \mathrm{C} 9$ & A6D0D935 & 48DAF 523 & F0B51DEF \\
\hline$t$ & $=59:$ & $8 \mathrm{FF} 296 \mathrm{DB}$ & $\mathrm{BE} 2 \mathrm{~A} 4656$ & $56 \mathrm{E} 30 \mathrm{CF} 2$ & A6D0D935 & 48DAF 523 \\
\hline$t$ & $=60:$ & C10C8993 & $8 F F 296 D B$ & AF $8 A 9195$ & $56 \mathrm{E} 30 \mathrm{CF} 2$ & A6D0D935 \\
\hline$t$ & $=61:$ & $6 \mathrm{AC} 23 \mathrm{CBF}$ & C10C8993 & E3FCA $5 B 6$ & AF $8 A 9195$ & $56 \mathrm{E} 30 \mathrm{CF} 2$ \\
\hline$t$ & $=62:$ & $0708247 D$ & $6 \mathrm{AC} 23 \mathrm{CBF}$ & F0432264 & E3FCA $5 B 6$ & AF $8 A 9195$ \\
\hline$t$ & $=63:$ & $35 \mathrm{D} 201 \mathrm{~F} 8$ & $0708247 D$ & $\mathrm{DAB} 08 \mathrm{~F} 2 \mathrm{~F}$ & F0432264 & E3FCA 5 B6 \\
\hline$t$ & $=64:$ & $969 \mathrm{~B} 2 \mathrm{FC} 8$ & $35 \mathrm{D} 201 \mathrm{~F} 8$ & $41 \mathrm{C} 2091 \mathrm{~F}$ & $\mathrm{DAB} 08 \mathrm{~F} 2 \mathrm{~F}$ & F0432264 \\
\hline$t$ & $=65:$ & $3 \mathrm{CAC} 6514$ & $969 \mathrm{~B} 2 \mathrm{FC} 8$ & OD74807E & $41 \mathrm{C} 2091 \mathrm{~F}$ & DAB08F $2 F$ \\
\hline$t$ & $=66:$ & $14 \mathrm{CD} 9 \mathrm{~A} 35$ & $3 \mathrm{CAC} 6514$ & $25 \mathrm{~A} 6 \mathrm{CBF} 2$ & OD74807E & $41 \mathrm{C} 2091 \mathrm{~F}$ \\
\hline$t$ & $=67:$ & BA 564047 & $14 \mathrm{CD} 9 \mathrm{~A} 35$ & OF $2 B 1945$ & $25 \mathrm{~A} 6 \mathrm{CBF} 2$ & OD74807E \\
\hline$t$ & $=68:$ & C241F74D & BA 564047 & $4533668 D$ & OF $2 B 1945$ & $25 \mathrm{~A} 6 \mathrm{CBF} 2$ \\
\hline t & $=69:$ & $2896 \mathrm{~B} 70 \mathrm{~F}$ & C241F74D & EE959011 & $4533668 D$ & OF 2 B 1945 \\
\hline t & $=70:$ & 564 BBED 1 & $2896 \mathrm{~B} 70 \mathrm{~F}$ & $70907 \mathrm{DD} 3$ & EE959011 & $4533668 D$ \\
\hline$t$ & $=71:$ & $8 F A 15 D 5 A$ & $564 \mathrm{BBED} 1$ & $\mathrm{CA} 25 \mathrm{ADC} 3$ & $70907 \mathrm{DD} 3$ & EE959011 \\
\hline$t$ & $=72:$ & $9 A 226 C 11$ & $8 F A 15 D 5 A$ & 5592ЕFB4 & CA25ADC3 & $70907 \mathrm{DD} 3$ \\
\hline$t$ & $=73:$ & FOB9 4489 & $9 A 226 C 11$ & A3E85756 & 5592 EFB4 & CA2 $5 A D C 3$ \\
\hline$t$ & $=74:$ & 1809D5E2 & F0B9 4489 & 66889 B04 & A3E85756 & 5592 EFB4 \\
\hline$\tau$ & 75 : & B8 6 C 5 A 40 & 1809D5E2 & $7 C 2 \mathrm{E} 5122$ & $66889 \mathrm{~B} 04$ & A3E85756 \\
\hline$t$ & $=76:$ & DFE7E487 & B86C5A40 & 86027578 & $7 \mathrm{C} 2 \mathrm{E} 5122$ & $66889 \mathrm{~B} 04$ \\
\hline$\tau$ & $=77$ & $70286 C 07$ & DFE7E487 & 2E1B1690 & 86027578 & $7 \mathrm{C} 2 \mathrm{E} 5122$ \\
\hline$t$ & $=78:$ & 24FF7ED5 & $70286 C 07$ & F7F9F921 & 2E1B1690 & 86027578 \\
\hline$c$ & $=79:$ & 9A1F95A8 & 24FF7ED5 & $\mathrm{DC} 0 \mathrm{~A} 1 \mathrm{~B} 01$ & F7F9F921 & 2Е1B169 \\
\hline
\end{tabular}

After processing, the hex values of $\left\{\mathrm{H}_{\mathrm{i}}\right\}$ are

$\mathrm{H}_{0}=67452301+9 A 1 F 95 A 8=0164 \mathrm{~B} 8 \mathrm{~A} 9$
$\mathrm{H}_{1}=$ EFCDAB89
$\mathrm{H}_{2}=98 \mathrm{BADCFE}+24 \mathrm{FF} 7 \mathrm{ED} 5=14 \mathrm{CD} 2 \mathrm{~A} 5 \mathrm{E}$
$\mathrm{H}_{3}=10325476+$ FCOA1B01
$\mathbf{H}_{4}=$ C3D2E1F0 + 2E1B1690 $21=082 \mathrm{~F} 7 \mathrm{FF}$

Message digest $=0164 \mathrm{~B} 8 \mathrm{~A} 9 \quad 14 \mathrm{CD} 2 \mathrm{~A} 5 \mathrm{E} \quad 74 \mathrm{C} 4 \mathrm{~F} 7 \mathrm{FF} \quad 082 \mathrm{C} 4 \mathrm{D} 97 \quad \mathrm{~F} 1 \mathrm{EDF} 880$ 


\section{APPENDIX B. A SECOND SAMPLE MESSAGE AND ITS MESSAGE DIGEST}

This appendix is for informational purposes only and is not required to meet the standard.

Let the message be the binary-coded form (cf. Appendix A) of the ASCII string "abcdbcdecdefdefgefghfghighijhijkijkljklmklmnlmnomnopnopq".

Since each of the 56 characters is converted to 8 bits, the length of the message is $l=448$. In step (a) of Section 4, we append "1". In step (b) we append 511 "0"s. In step (c) we append the 2 -word representation of 448, i.e., hex $00000000000001 C 0$. This gives $n=2$.

The initial hex values of $\left\{\mathrm{H}_{\mathrm{i}}\right\}$ are

$$
\begin{aligned}
& \mathbf{H}_{0}=67452301 \\
& \mathbf{H}_{1}=\text { EFCDAB89 } \\
& \mathbf{H}_{2}=98 B A D C F E \\
& \mathbf{H}_{3}=10325476 \\
& \mathbf{H}_{4}=\text { C3D } 2 \mathrm{E} 1 \mathrm{~F} 0 .
\end{aligned}
$$

Start processing block 1. The words of block 1are

$$
\begin{array}{ll}
\mathrm{W}[0] & =61626364 \\
\mathrm{~W}[1] & =62636465 \\
\mathrm{~W}[2] & =63646566 \\
\mathrm{~W}[3] & =64656667 \\
\mathrm{~W}[4] & =65666768 \\
\mathrm{~W}[5] & =66676869 \\
\mathrm{~W}[6] & =6768696 \mathrm{~A} \\
\mathrm{~W}[7] & =68696 \mathrm{~A} 6 \mathrm{~B} \\
\mathrm{~W}[8] & =696 \mathrm{~A} 6 \mathrm{~B} 6 \mathrm{C} \\
\mathrm{W}[9] & =6 \mathrm{~A} 6 \mathrm{~B} 6 \mathrm{C} 6 \mathrm{D} \\
\mathrm{W}[10] & =6 \mathrm{~B} 6 \mathrm{C} 6 \mathrm{D} 6 \mathrm{E} \\
\mathrm{W}[11] & =6 \mathrm{C} 6 \mathrm{D} 6 \mathrm{E} 6 \mathrm{~F} \\
\mathrm{~W}[12] & =6 \mathrm{D} 6 \mathrm{E} 6 \mathrm{~F} 70 \\
\mathrm{~W}[13] & =6 \mathrm{E} 6 \mathrm{~F} 7071 \\
\mathrm{~W}[14] & =80000000 \\
\mathrm{~W}[15] & =00000000 .
\end{array}
$$

The hex values of A,B,C,D,E after pass $t$ of the "for $t=0$ to 79" loop (step (d) of Section 7 or (c) of Section 8) are 
A

$t$

$t=1:$ EBF3B452

$t=2: 5109913 \mathrm{~A}$

$t=3: 2 \mathrm{C} 4 \mathrm{~F} 6 \mathrm{EAC}$

$t=4: 33 \mathrm{~F} 4 \mathrm{AE} 5 \mathrm{~B}$

$t=5: 96 \mathrm{~B} 85189$

$t=6: \mathrm{DB} 04 \mathrm{CB} 58$

$t=7: 45833 \mathrm{~F} 0 \mathrm{~F}$

$t=8: C 565 \mathrm{C} 35 \mathrm{E}$

$t=9:$ 6350AFDA

$t=10: 8993 \mathrm{EA} 77$

$t=11:$ E19ECAA2

$t=12: 8603481 \mathrm{E}$

$t=13: 32 \mathrm{~F} 94 \mathrm{~A} 85$

$t=14: \mathrm{B} 2 \mathrm{E} 7 \mathrm{~A} 8 \mathrm{BE}$

$t=15: 42637 \mathrm{E} 39$

$t=16: 66036329$

$t=17:$ B59A89E4

$t=18: 90 B 9433 \mathrm{E}$

$t=19:$ DB5227E2

$t=20: 91241034$

$t=21: 4 \mathrm{C} 06 \mathrm{BD} 64$

$t=22: 8665831 \mathrm{E}$

$t=23: 3 \mathrm{~F} 62 \mathrm{D} 9 \mathrm{EC}$

$t=24: C D 40 E 178$

$t=25: D 83 E 484 E$

$t=26: D 70940 \mathrm{FE}$

$t=27: 39 \mathrm{~B} 6981 \mathrm{~B}$

$t=28: 694303 \mathrm{AE}$

$t=29: 8 \mathrm{E} 08 \mathrm{FDOA}$

$t=30:$ FBFF1BA5

$t=31: 8 A B 96092$

$t=32: 4206057 \mathrm{~A}$

$t=33: 2$ CBCFC1A

$t=34: 505759 \mathrm{~F} 3$

$t=35:$ 05BB8EC9

$t=36: A 0 F C 08 \mathrm{~A} 0$

$t=37: 8664 \mathrm{~F} 5 \mathrm{E} 1$

$t=38:$ FE3D2A $4 F$

$t=39:$ 07D02AA9

$t=40: 38 D 7321 \mathrm{C}$

$t=41: 1 \mathrm{~F} 3 \mathrm{CA} 4 \mathrm{C} 0$

$t=42:$ DF27AAOC

$t=43: 84 \mathrm{E} 2 \mathrm{DBA} 6$

$t=44: 8797 \mathrm{~EB} 77$

$t=45: 9 D 220100$

$t=46:$ CB326B71

$t=47: 505 D E 66 \mathrm{~F}$

$t=48:$ FFDF8E6F
67452301

0116 FC17

EBF3B452

5109913A

2C4F6EAC

33F 4 AE $5 B$

$96 \mathrm{~B} 85189$

DB0 4CB5 8

45833F0F

C565C35E

6350AFDA

8993 EA 77

E19ECAA2

$8603481 \mathrm{E}$

32F94A 85

B2E7A8BE

42637 E39

66036329

B59A89E4

90B9433E

DB5227E2

91241034

$4 \mathrm{C} 06 \mathrm{BD} 64$

$8665831 \mathrm{E}$

3F62D9EC

CD4 0E178

D83E484E

D70940FE

39B6981B

694303AE

8E08FD0A

FBFF1BA5

8 AB9 6092

$4206057 \mathrm{~A}$

2CBCFC1A

505759F3

05BB8EC9

A $0 F C 08 A 0$

8664 F5E1

FE3D2A4F

07D02AA9

38D7321C

$1 \mathrm{~F} 3 \mathrm{CA} 4 \mathrm{C} 0$

DF27AAOC

84E2DBA 6

8797 EB7 7

9D220100

CB326B71

505DE66F
C

7BF3 6AE2

59D148C0

C045BF0 5

BAFCED14

9442644E

OB13DBAB

CCFD2B9 6

65AE 1462

36C132D 6

D160CFC3

B15970D7

98D42BF6

E2 64FA9D

B867B2A 8

A180D207

4CBE52A1

ACB9EA2F

5098DF8E

5980D8CA

2D66A279

A 42 E5 0CF

B6D489F 8

244904 OD

1301AF59

A19960C7

OFD8B67B

$3350385 \mathrm{E}$

B60F9213

B5C $2503 \mathrm{~F}$

CE6DA606

$9 A 50 C 0 E B$

A 3 823F42

7 EFFC 6 E9

A2AE5824

$9081815 \mathrm{E}$

8B2F3F06

D415D67C

416 EE3B2

283F0228

61993D78

FF8F4A93

41F40AAA

0E3 5CC 87

07CF 2930

37C9EA 83

A138B6E9

E1E5FADD

27488040

$72 \mathrm{CC} 9 \mathrm{ADC}$
D

98BADCFE

7BF3 6AE2

59D148C 0

C045BF0 5

BAFCED14

$9442644 \mathrm{E}$

OB13DBAB

CCFD2B9 6

65AE1462

36C132D 6

D160CFC3

B15970D7

98D42BF 6

E264FA9D

B867B2A 8

A180D2 07

4CBE52A1

ACB9EA2F

5098DF8E

5980D8CA

2D66A279

A 42 E5 0CF

$\mathrm{B} 6 \mathrm{D} 489 \mathrm{~F} 8$

244904 OD

1301AF59

A19960C7

0FD8B67B

$3350385 \mathrm{E}$

B60F9213

B5C2503F

CE6DA606

$9 A 50 C 0 E B$

A3823F42

7 EFFC6E9

A2AE5824

$9081815 \mathrm{E}$

8B2F3F06

D415D67C

$416 \mathrm{EE} 3 \mathrm{~B} 2$

283F0228

61993D78

FF8F4A93

41F40AAA

0E35CC 87

07CF 2930

37C9EA83

A138B6E9

E1E5FADD

27488040
E

10325476

98BADCFE

$7 \mathrm{BF} 36 \mathrm{AE} 2$

59D148C0

C045BF0 5

BAFCED14

9442644E

OB13DBAB

CCFD2B9 6

65AE1462

36C132D6

D160CFC3

B15970D7

98D42BF 6

E264FA9D

B867B2A8

A180D207

4CBE52A1

ACB9EA2F

5098DF8E

5980D8CA

2D66A279

A 42E50CF

$\mathrm{B} 6 \mathrm{D} 489 \mathrm{~F} 8$

244904 OD

1301AF59

A19960C7

OFD8B67B

3350385E

B60F9213

B5C2503F

CE6DA606

$9 A 50 C 0 E B$

A3823F42

7EFFC6E9

A2AE5824

$9081815 \mathrm{E}$

8B2F3F06

D415D67C

416 EE3B2

283F0228

61993D78

FF8F4A93

41F4 OAAA

0E35CC87

07CF2930

37C9EA 83

A138B6E9

E1E5FADD 


\begin{tabular}{|c|c|c|c|}
\hline & $=49:$ & $47 \mathrm{~A} 17 \mathrm{~A} 6 \mathrm{~F}$ & $2-6$ \\
\hline & $=50:$ & $2 \mathrm{C} 742 \mathrm{CF} 4$ & $47 \mathrm{~A} 17$ \\
\hline & $=51:$ & $692 \mathrm{C} 82 \mathrm{~F} 3$ & $2 \mathrm{C} 742 \mathrm{C}$ \\
\hline & $=52:$ & 741A7AEB & $692 C 8$ \\
\hline & $=53:$ & E89625B3 & $11 \mathrm{~A} 72$ \\
\hline & $=54:$ & BB527C 29 & E89625 \\
\hline & $=55:$ & $609 A 8616$ & BB527C \\
\hline & $=56:$ & 5E259CED & $609 A 8$ \\
\hline & $=57:$ & FDCE $04 C 4$ & $5 \mathrm{E} 2$ \\
\hline & $=58:$ & $2 \mathrm{~A} 35958 \mathrm{~F}$ & FDCEO \\
\hline & $=59:$ & $029 A 9 D B B$ & $2 \mathrm{~A} 35$ \\
\hline & $=60:$ & $651604 \mathrm{AB}$ & 029A9I \\
\hline & $=61:$ & $3 F 163 F 73$ & 651604 \\
\hline & $=62:$ & $60 E 30527$ & $3 F 163 F$ \\
\hline & $=63:$ & DA53F35E & 60 E305 \\
\hline & $=64:$ & $59 F 8 E 302$ & DA53F3 \\
\hline & $=65:$ & BE75732C & $59 F 8 E 3$ \\
\hline & $=66:$ & 8D8DFD49 & BE7573 \\
\hline & $=67:$ & $556247 \mathrm{FC}$ & 8D8DFD \\
\hline & $=68:$ & C416C3E2 & 5562471 \\
\hline & $=69:$ & $64 \mathrm{C} 244 \mathrm{C} 9$ & C416C31 \\
\hline & $=70:$ & B0DF5B97 & $64 C 244 C$ \\
\hline & $=71:$ & $905723 \mathrm{FE}$ & B0DF5B \\
\hline & $=72:$ & 49946022 & 905723 \\
\hline & $=73:$ & B3 A 64DB3 & 499460 \\
\hline & $=74:$ & $281589 B C$ & B3A64DI \\
\hline & $=75:$ & $4623888 D$ & 281589 \\
\hline & $=76$ & $74 \mathrm{~EB} 04 \mathrm{~B} 7$ & 46238 \\
\hline & $=77$ & $035 \mathrm{D} 4 \mathrm{CD} 9$ & $74 \mathrm{~EB} 04$ \\
\hline & $=7 \varepsilon$ & $\mathrm{B} 2 \mathrm{BDD} 7 \mathrm{D} 0$ & $035 D$ \\
\hline & $=$ & 1D750196 & \\
\hline
\end{tabular}

D417799B
FFF7E39B
D1E85E9B
OB1D0B3D
DA4B20BC
DD069EBA
FA25896C
6ED49F0A
9826 A 185
$5789673 B$
$3 F 738131$
CA 86563
C0A6A76E
D945812A
CFC58FDC
D838C149
B694FCD7
$967 E 38 C 0$
$2 F 9 D 5 C C B$
$63637 F 52$
155891FF
B105BOF8
59309132
EC37D6E5
A415C8FF
92651808
ECE9936C
0A05626F
$5188 E 223$
DD3AC12D
$40 D 75336$

72CC9ADC

27488040

72CC9ADC

D417799B

FFF7E39B

D1E85E9B

OB1D0B3D

DA 4B2 0BC

DD0 69EBA

FA25896C

6ED49F0A

9826A185

$5789673 B$

3F738131

CA8D6563

C0A6A76E

D945812A

CFC58FDC

D838C149

B694FCD7

$967 \mathrm{E} 38 \mathrm{C} 0$

2F9D5CCB

$63637 F 52$

$155891 \mathrm{FF}$

B1 05B0F 8

59309132

EC37D6E5

$\mathrm{A} 415 \mathrm{C} 8 \mathrm{FF}$

92651808

ECE9936C

OA05626F

$5188 \mathrm{E} 223$.

Block 1 has been processed. The values of $\left\{H_{i}\right\}$ are

\begin{tabular}{|c|c|c|c|c|}
\hline $\mathbf{H}_{0}=67452301$ & + & 1D750196 & $=$ & $84 \mathrm{BA} 2497$ \\
\hline $\mathrm{H}_{1}=\mathrm{EFCDAB} 89$ & + & $\mathrm{B} 2 \mathrm{BDD} 7 \mathrm{D} 0$ & $=$ & A28B8359 \\
\hline $\mathrm{H}_{2}=98 \mathrm{BADCFE}$ & + & $40 D 75336$ & $=$ & D9923034 \\
\hline$H_{3}=10325476$ & + & $\mathrm{DD} 3 \mathrm{AC} 12 \mathrm{D}$ & $=$ & ED6D15A3 \\
\hline $\mathrm{H}_{4}=\mathrm{C} 3 \mathrm{D} 2 \mathrm{E} 1 \mathrm{~F} 0$ & + & $5188 E 223$ & $=$ & $155 \mathrm{BC} 413$ \\
\hline
\end{tabular}

Start processing block 2. The words of block 2 are

$$
\begin{array}{ll}
W[0] & =00000000 \\
W[1] & =00000000 \\
W[2] & =00000000
\end{array}
$$




$\begin{array}{ll}\mathrm{W}[3] & =00000000 \\ \mathrm{~W}[4] & =00000000 \\ \mathrm{~W}[5] & =00000000 \\ \mathrm{~W}[6] & =00000000 \\ \mathrm{~W}[7] & =00000000 \\ \mathrm{~W}[8] & =00000000 \\ \mathrm{~W}[9] & =00000000 \\ \mathrm{~W}[10] & =00000000 \\ \mathrm{~W}[11] & =00000000 \\ \mathrm{~W}[12] & =00000000 \\ \mathrm{~W}[1]] & =00000000 \\ \mathrm{~W}[14] & =00000000 \\ \mathrm{~W}[15] & =000001 C 0 .\end{array}$

The hex values of A,B,C,D,E after pass $t$ of the "for $t=0$ to 79" loop (step (d) of Section 7 or (c) of Section 8) are

A

\begin{tabular}{|c|c|c|}
\hline & : & D508E54E \\
\hline & $=$ & $9 \mathrm{CC}$ \\
\hline & $2:$ & $738 \mathrm{C} 64 \mathrm{E} 9$ \\
\hline & $=$ & $\mathrm{D} 5 \mathrm{~B} 4 \mathrm{AOFE}$ \\
\hline & $=$ & $870 F 3 \mathrm{COB}$ \\
\hline & $=$ & 4657 \\
\hline & $=$ & $02 \mathrm{~F}$ \\
\hline & $=$ & $6 \mathrm{DF}$ \\
\hline & $8:$ & $5 \mathrm{CE} 2$ \\
\hline & $=$ & $10 D^{\prime}$ \\
\hline & $=10:$ & $0 \mathrm{C}^{2}$ \\
\hline & $=1$ & $6 \mathrm{EA}$ \\
\hline & $=12$ & $7 E$ \\
\hline & $=1$. & F96 \\
\hline & $=1$ & $26 \mathrm{~F}$ \\
\hline & $=1$ & 156 \\
\hline & $=1$ & 629 \\
\hline & $=17$ & B812 \\
\hline & $=1 \varepsilon$ & A562 \\
\hline & $=15$ & 2DBC $9 \mathrm{CFF}$ \\
\hline & $=20$ & $\mathrm{BF} 89 \mathrm{C} 409$ \\
\hline & $=21$ & $239 A 6 D 9 B$ \\
\hline & $=22$ & ADEC 9CD5 \\
\hline & $=23$ & $1 \mathrm{CDD} 463$ \\
\hline & $=24$ & EODA \\
\hline & $=25$ & B947 \\
\hline & $=2$ & $\mathrm{AD} 4 \mathrm{~F}$ \\
\hline & $=2$ & CA67CF \\
\hline & $=2$ & FE34397 \\
\hline & $=2$ & חב \\
\hline & $=3$ & E4D7 \\
\hline
\end{tabular}

$\mathrm{B}$

$84 \mathrm{BA} 2497$ D508E54E $42 \mathrm{AE} 69 \mathrm{CC}$ $738 \mathrm{C} 64 \mathrm{E} 9$ D5B4A0FE $870 \mathrm{~F} 3 \mathrm{COB}$ $46574 \mathrm{E} 97$ $1405102 \mathrm{~F}$ 297306DF $30185 \mathrm{CE} 2$ 10D7BA0C 0C $28 \mathrm{CF} 6 \mathrm{~B}$ 6EABFEC 0 7 E $85 F 170$ F964F1A3 26E19055 $156937 \mathrm{E7}$ 6295F273 B81A706E A5620A0D 2DBC9CFF BF 89C409 239A6D9B ADEC 9 CD 5 1CDD463F E0DA5334 B9 47BDAB AD4E620C CA67CF 14 FE343974 7CFD680A
C

68A2E0D6 E12E8925 B5423953 10AB9A73 5CE3193A B56D283F E1C3CF 02 D195D3A 5 C501440B CA5CC $1 B 7$ $8 C 061738$ 0435 EE 83 C30A33DA 1BAAFFB0 $1 \mathrm{FA} 17 \mathrm{C} 5 \mathrm{C}$ FE593C68 $49 B 86415$ C55A4DF 9 D8A57C9C AE0 69C1B 69588283 CB6F273F 6FE27102 C8E69B6 6 6B7B2735 C737518F 383694CD EE51EF6A 2B539883 3299 F 3 C5 3F8D0E5D
D9923034 68A2 E0D6 E12E8925 B5423953 10AB9A73 5CE3193A B56D283F E1C3CF 02 D195D3A 5 C501440B CA 5 CC $1 B 7$ 8C061738 0435 EE83 C30A33DA $1 \mathrm{BAAFFB} 0$ 1FA17C5C FE593C68 49B86415 C55A4DF 9 D8A57C9C AE0 69C1B 69588283 CB6F273F 6FE2 7102 C8E69B6 6 6B7B2735 C737518F $383694 \mathrm{CD}$ EE51EF6A 2 B539883 3299F3C5
E

ED6D15A3 D9923034 68A2E0D6 E12E8925 B5423953 10AB9A73 5CE3193A B56D283F E1C3CF 02 D195D3A5 C501440B CA5CC1B7 8C061738 0435EE83 C30A33DA $1 \mathrm{BAAFFB} 0$ 1FA17C5C FE593C68 49B86415 C55A4DF 9 D8A57C9C AE0 69C1B 69588283 CB6F273F 6FE27102 C8E69B6 6 6B7B2735 C737518F $383694 \mathrm{CD}$ EE51EF6A 2B539883 


\begin{tabular}{|c|c|c|c|c|c|c|}
\hline & $=31:$ & A6FD2352 & E4D7304C & $9 \mathrm{~F} 3 \mathrm{~F} 5 \mathrm{~A} 02$ & 3F8D0E5D & $3299 F 3 C 5$ \\
\hline$t$ & $=32:$ & C57DADCD & A6FD2352 & $3935 \mathrm{CC} 13$ & $9 F 3 F 5 A 02$ & 3F8D0E5D \\
\hline$t$ & $=33:$ & $5 F 146 \mathrm{AB} 9$ & C57DADCD & $\mathrm{A} 9 \mathrm{BF} 48 \mathrm{D} 4$ & $3935 \mathrm{CC} 13$ & $9 F 3 F 5 A 02$ \\
\hline t & $=34:$ & 469DC798 & $5 F 146 A B 9$ & $715 \mathrm{~F} 6 \mathrm{~B} 73$ & A9BF 48D4 & $3935 C_{C C} 13$ \\
\hline t & $=35:$ & $03 \mathrm{BCF} 3 \mathrm{DA}$ & $469 D C 798$ & 57C51AAE & $715 \mathrm{~F} 6 \mathrm{~B} 73$ & A9BF 48D4 \\
\hline t & $=36:$ & F03F67BA & $03 B C F 3 D A$ & 11A771E6 & 57C51AAE & $715 \mathrm{~F} 6 \mathrm{~B} 73$ \\
\hline$t$ & $=37:$ & $2 \mathrm{E} 04 \mathrm{E} 8 \mathrm{C} 4$ & F03F67BA & $80 \mathrm{EF} 3 \mathrm{CF} 6$ & 11A771E6 & 57C51AAE \\
\hline$t$ & $=38:$ & E8B3497E & $2 \mathrm{E} 04 \mathrm{E} 8 \mathrm{C} 4$ & BCOFD9EE & $80 \mathrm{EF} 3 \mathrm{CF} 6$ & $11 \mathrm{~A} 771 \mathrm{E} 6$ \\
\hline$t$ & $=39:$ & A9СE9B40 & E8B3497E & $0 B 813 A 31$ & BC0FD9EE & $80 \mathrm{EF} 3 \mathrm{CF} 6$ \\
\hline$t$ & $=40:$ & F261BB 65 & A9CE9B40 & $\mathrm{BA} 2 \mathrm{CD} 25 \mathrm{~F}$ & OB813A31 & BCOFD9EE \\
\hline$t$ & $=41:$ & 42EF9DD9 & F261BB 65 & $2 \mathrm{~A} 73 \mathrm{~A} 6 \mathrm{D} 0$ & $\mathrm{BA} 2 \mathrm{CD} 25 \mathrm{~F}$ & OB813A31 \\
\hline$t$ & $=42:$ & $\mathrm{B} 2 \mathrm{~F} 2664 \mathrm{~A}$ & 42EF9DD9 & 7C986ED9 & 2A73A6D0 & $\mathrm{BA} 2 \mathrm{CD} 25 \mathrm{~F}$ \\
\hline$t$ & $=43:$ & $1291092 \mathrm{~A}$ & B2F2664A & $50 \mathrm{BBE} 776$ & 7C986ED9 & 2A73A6D0 \\
\hline$t$ & $=44:$ & 7C6AEF 48 & $1291092 \mathrm{~A}$ & ACBC 9992 & 50ВВЕ776 & 7C986ED9 \\
\hline$t$ & $=45:$ & A9CB9DF 6 & 7С6АEF 48 & $84 \mathrm{~A} 4424 \mathrm{~A}$ & АCBC 9992 & $50 B B E 776$ \\
\hline$t$ & $=46:$ & C5F82E71 & A9CB9DF 6 & $1 \mathrm{~F} 1 \mathrm{ABBD} 2$ & $84 A 4424 A$ & ACBC 9992 \\
\hline$t$ & $=47:$ & $8868 C 238$ & C5F82E71 & AA72E77D & 1F1ABBD2 & $84 A 4424 A$ \\
\hline$t$ & $=48:$ & B052F768 & $8868 C 238$ & 717 ЕОВ9С & AA72E77D & $1 \mathrm{~F} 1 \mathrm{ABBD} 2$ \\
\hline$t$ & $=49:$ & $61102 \mathrm{ACO}$ & B052F768 & $221 A 308 E$ & 717 ЕОВ9С & AA72E77D \\
\hline$t$ & $=50:$ & 8BEE2FF1 & $61102 \mathrm{AC} 0$ & $2 \mathrm{C} 14 \mathrm{BDDA}$ & $221 A 308 E$ & 717 ЕОВ9С \\
\hline$t$ & $=51:$ & $9 E 700133$ & 8BEE2FF1 & $18440 \mathrm{AB} 0$ & $2 \mathrm{C} 14 \mathrm{BDDA}$ & $221 \mathrm{~A} 308 \mathrm{E}$ \\
\hline$t$ & $=52:$ & $877 A 43 C D$ & $9 E 700133$ & $62 \mathrm{FB} 8 \mathrm{BFC}$ & $18440 \mathrm{ABO}$ & $2 \mathrm{C} 14 \mathrm{BDDA}$ \\
\hline$t$ & $=53:$ & C4E901D6 & $877 A 43 C D$ & E79C004C & $62 \mathrm{FB} 8 \mathrm{BFC}$ & $18440 \mathrm{AB} 0$ \\
\hline$t$ & $=54:$ & 2C7A07F0 & C4E901D6 & 61DE90F3 & E79C004C & $62 \mathrm{FB} 8 \mathrm{BFC}$ \\
\hline$t$ & $=55:$ & 67344973 & 2C7A07F0 & B13A4075 & 61DE90F3 & E79C004C \\
\hline$t$ & $=56:$ & 7ЕBAEE4 5 & 67344973 & OB1E81FC & B13A4075 & 61DE90F3 \\
\hline$t$ & $=57:$ & EB9659B3 & $7 \mathrm{EBAEE} 45$ & D9CD125C & OB1E81FC & B13A4075 \\
\hline$t$ & $=58:$ & OЕВFB $62 \mathrm{~A}$ & EB9659B3 & 5 FAEBB 91 & D9CD125C & 0B1E81FC \\
\hline$t$ & $=59:$ & $4 \mathrm{DBF} 216 \mathrm{~A}$ & OЕВFB $62 \mathrm{~A}$ & FAE5966C & 5 FAEBB 91 & D9CD125C \\
\hline$t$ & $=60:$ & $08089 F 12$ & $4 \mathrm{DBF} 216 \mathrm{~A}$ & 83AFED8A & FAE5966C & $5 \mathrm{FAEBB} 91$ \\
\hline$t$ & $=61:$ & $601 \mathrm{ABA} 34$ & $08089 F 12$ & $936 \mathrm{FC} 85 \mathrm{~A}$ & 83AFED8A & FAE5966C \\
\hline$t$ & $=62:$ & E1685B50 & $601 \mathrm{ABA} 34$ & $820227 C 4$ & $936 \mathrm{FC} 85 \mathrm{~A}$ & 83AFED8A \\
\hline$t$ & $=63:$ & EC956F26 & E1685B50 & $1806 \mathrm{AE} 8 \mathrm{D}$ & $820227 C 4$ & $936 \mathrm{FC} 85 \mathrm{~A}$ \\
\hline$t$ & $=64:$ & 6BED4126 & EC956F26 & $385 \mathrm{~A} 16 \mathrm{D} 4$ & $1806 \mathrm{AE} 8 \mathrm{D}$ & $820227 C 4$ \\
\hline$t$ & $=65:$ & 96D6E5E6 & 6BED4126 & $\mathrm{BB} 255 \mathrm{BC} 9$ & $385 \mathrm{~A} 16 \mathrm{D} 4$ & $1806 \mathrm{AE} 8 \mathrm{D}$ \\
\hline$t$ & $=66:$ & A5D83970 & 96D6E5E6 & 9AFB5049 & ВB2 55 BC 9 & $385 \mathrm{~A} 16 \mathrm{D} 4$ \\
\hline$t$ & $=67:$ & $74 \mathrm{CCF} 6 \mathrm{E} 4$ & A5D83970 & A $5 B 5 B 979$ & 9AFB5049 & BB2 55 BC 9 \\
\hline$t$ & $=68:$ & B9BDCA6D & 74CCF6E4 & $29760 \mathrm{E} 5 \mathrm{C}$ & А 5 B 5 B 979 & 9AFB5049 \\
\hline$t$ & $=69:$ & $9526 A 197$ & B9BDCA6D & 1D333DB9 & $29760 \mathrm{E} 5 \mathrm{C}$ & А 5 B 5 B 979 \\
\hline$t$ & $=70:$ & A2E 5 A 7 C 9 & $9526 A 197$ & 6Е6F729B & 1D333DB9 & $29760 \mathrm{E} 5 \mathrm{C}$ \\
\hline$t$ & $=71:$ & $3708 B 81 B$ & A2E5A7C9 & E549A865 & 6 E6F729B & 1D333DB9 \\
\hline$t$ & $=72:$ & F27081EC & $3708 B 81 B$ & $68 B 969 F 2$ & E549A865 & $6 \mathrm{E} 6 \mathrm{~F} 729 \mathrm{~B}$ \\
\hline$t$ & $=73:$ & 41DAEB9B & F27081EC & CDC22E06 & $68 \mathrm{~B} 969 \mathrm{~F} 2$ & E549A865 \\
\hline$t$ & $=74:$ & $4215 A 57 B$ & 41DAEB9B & $3 \mathrm{C} 9 \mathrm{C} 207 \mathrm{~B}$ & CDC $22 \mathrm{E} 06$ & $68 \mathrm{~B} 969 \mathrm{~F} 2$ \\
\hline 5 & $=75:$ & $2655 \mathrm{C} 2 \mathrm{D} 6$ & $4215 A 57 B$ & D076BAE6 & $3 \mathrm{C} 9 \mathrm{C} 207 \mathrm{~B}$ & CDC2 2E06 \\
\hline$t$ & $=76:$ & 11DC8A86 & $2655 \mathrm{C} 2 \mathrm{D} 6$ & D085695E & D076BAE6 & $3 \mathrm{C} 9 \mathrm{C} 207 \mathrm{~B}$ \\
\hline & $=77:$ & 69364641 & 11DC8A86 & $899570 B 5$ & D085695E & D076BAE6 \\
\hline & $=78:$ & OA6ED856 & 69364641 & $847722 \mathrm{~A} 1$ & $899570 B 5$ & D085695E \\
\hline & $=79:$ & $4 \mathrm{D} 974 \mathrm{~A} 4 \mathrm{~A}$ & 0A6ED856 & $5 A 4 D 9190$ & $847722 \mathrm{~A} 1$ & $899570 B 5$ \\
\hline
\end{tabular}


Block 2 has been processed. The values of $\left\{\mathrm{H}_{\mathrm{i}}\right\}$ are

$\mathbf{H}_{0}=84 \mathrm{BA} 2497+4 \mathrm{D} 974 \mathrm{~A} 4 \mathrm{~A}+\mathrm{D} 2516 \mathrm{EE} 1$
$\mathrm{H}_{1}=\mathrm{A} 28 \mathrm{~B} 8359+0 \mathrm{~A} 6 \mathrm{ED} 856=$ ACFA5BAF
$\mathrm{H}_{2}=\mathrm{D} 9923034+5 \mathrm{~A} 4 \mathrm{D} 9190=33 \mathrm{DFC} 1 \mathrm{C} 4$
$\mathrm{H}_{3}=\mathrm{ED} 6 \mathrm{D} 15 \mathrm{~A} 3+847722 \mathrm{~A} 1=71 \mathrm{E} 43844$
$\mathbf{H}_{4}=155 \mathrm{BC} 413+899570 \mathrm{~B} 5=9 \mathrm{EF} 134 \mathrm{C} 8$.

Message digest $=\mathrm{D} 2516 \mathrm{EE} 1$ ACFA5BAF $33 \mathrm{DFC} 1 \mathrm{C} 4 \quad 71 \mathrm{E} 43844 \quad 9 \mathrm{EF} 134 \mathrm{C} 8$ 


\section{APPENDIX C. A THIRD SAMPLE MESSAGE AND ITS MESSAGE DIGEST}

This appendix is for informational purposes only and is not required to meet the standard.

Let the message be the binary-coded form of the ASCII string which consists of $1,000,000$ repetitions of "a".

Message digest $=3232 \mathrm{AFFA}$ 48628A26 653B5AAA 44541FD9 0D690603 


\section{U.S. Department of Commerce}

National Technical Information Service

5285 Port Royal Road

Springfield, VA 22161

Official Business

Penalty for Private Use $\$ 300$ 